\title{
Measurement of dietary intake in children
}

\author{
M. B. E. Livingstone* and P. J. Robson \\ Northern Ireland Centre for Diet and Health, University of Ulster, Coleraine, Co. Londonderry BT52 1SA, UK
}

\begin{abstract}
When children and adolescents are the target population in dietary surveys many different respondent and observer considerations surface. The cognitive abilities required to self-report food intake include an adequately developed concept of time, a good memory and attention span, and a knowledge of the names of foods. From the age of 8 years there is a rapid increase in the ability of children to self-report food intake. However, while cognitive abilities should be fully developed by adolescence, issues of motivation and body image may hinder willingness to report. Ten validation studies of energy intake data have demonstrated that mis-reporting, usually in the direction of under-reporting, is likely. Patterns of under-reporting vary with age, and are influenced by weight status and the dietary survey method used. Furthermore, evidence for the existence of subject-specific responding in dietary assessment challenges the assumption that repeated measurements of dietary intake will eventually obtain valid data. Unfortunately, the ability to detect mis-reporters, by comparison with presumed energy requirements, is limited unless detailed activity information is available to allow the energy intake of each subject to be evaluated individually. In addition, high variability in nutrient intakes implies that, if intakes are valid, prolonged dietary recording will be required to rank children correctly for distribution analysis. Future research should focus on refining dietary survey methods to make them more sensitive to different ages and cognitive abilities. The development of improved techniques for identification of mis-reporters and investigation of the issue of differential reporting of foods should also be given priority.
\end{abstract}

Childhood: Adolescents: Dietary intake

The accurate assessment of food intake in children and adolescents is of concern because dietary habits formed early in life in response to physiological requirements and psycho-social pressures may have considerable impact on long-term health status. When children and adolescents are the target population many different respondent and observer considerations surface at all ages from early childhood through to late adolescence (Table 1). Despite the unique methodological challenges posed, it is still tacitly assumed that currently available dietary survey methods, which were constructed for use in adult populations, are also appropriate for collecting data from paediatric populations. Undoubtedly, blending the method with respondent capability is of paramount importance, but to date the limits of accuracy of the various survey instruments when applied to children and adolescents have not been defined. Until they are, substantial progress in the development of new and/or the refinement of existing methodologies that are sensitive to different ages, cognitive abilities and motivation levels will be hampered.

The purpose of the present review is to: evaluate key measurement issues in the dietary assessment of children and adolescents; examine the issues of dietary mis-reporting and the identification of mis-reporters; identify key agerelated criteria when selecting dietary survey methods; highlight priority areas for research aimed at enhancing the quality of dietary data in these groups.

\section{Cognitive aspects of dietary reporting \\ Parental dietary recall}

Since young children ( $<7$ years old) have a limited ability to co-operate in dietary assessment, the ability of parents to accurately recall their children's food intake is vital. In dietary-recall studies which have compared the results of 
Table 1. Respondent-observer issues in the dietary assessment of children and adolescents

\begin{tabular}{ll}
\hline Childhood & Adolescence \\
\hline $\begin{array}{l}\text { Cognitive abilities } \\
\text { Low literacy skills }\end{array}$ & Full cognitive capability \\
Limited attention span & \\
Limited concept of time & \\
Limited memory & \\
Limited knowledge of food and & Extensive knowledge of food, but \\
food preparation & of food preparation? \\
Dietary reporting by surrogate & Onus of reporting on self \\
respondents & \\
Dietary habits & \\
Rapidly-changing food habits, & Rapidly-changing food habits, but \\
but (more) structured eating & unstructured eating patterns \\
patterns & \\
More in-home eating & More out-of-home eating \\
Under supervision of adults & Less supervised by adults \\
Parental influence important & Peer influence important \\
Psychological & \\
Food satisfies hunger & Food is a means of self- \\
& expression
\end{tabular}

direct observation of children's food intake with $24 \mathrm{~h}$ recalls by parents the evidence suggests that parents can be reliable reporters of their children's food intake in the home setting (Klesges et al. 1987, 1988; Eck et al. 1989; Basch et al. 1990; Baranowski et al. 1991). Unfortunately, many of these studies involved mainly well-educated parents who were present during the observations of their children's food intake. Moreover, the time period covered was often less than $24 \mathrm{~h}$. Nevertheless, these results are supported by an independent validation of energy intakes (EI) of children aged 4-7 years assessed by three $24 \mathrm{~h}$ recalls by parents (Johnson et al. 1996).

A major concern, however, is that parents are not reliable reporters of their children's food intake out-of-home. Baranowski et al. (1991) found that mothers of preschool children who were away from home more than $4 \mathrm{~h} / \mathrm{d}$ were less able to report on their children's food intake. However, when they could report they were as accurate as mothers who remained at home all day. Furthermore, socioeconomic status was not related to the accuracy of dietary reporting. Overall, mothers in this study were more likely to under-report $(18 \%)$ than over-report foods $(10 \%)$. Mothers' reports of children's food intake appear to provide acceptable estimates of mean intakes of energy and nutrients, but because of difficulties in estimating portion sizes eaten and under- and over-reporting of actual foods eaten, the accuracy of the recalls is poor at an individual level (Klesges et al. 1987, 1988; Eck et al. 1989; Basch et al. 1990; Baranowski et al. 1991).

In conclusion, it appears that parents can be reliable reporters of their children's food intake in the home environment, particularly if both parents participate in the reporting process (Eck et al. 1989). However, given that many parents now work out-of-home, the suitability of parents to be the only informants of their child's intake is inevitably limited, and this must be regarded as a major limiting factor in studies using recall methodology in young children.

\section{Portion size estimation}

The quantification of the amount of food eaten, other than by direct weighing, includes a largely unknown component of error. In the few studies that have attempted to assess the ability of children and adolescents to describe portion sizes, the results have been somewhat inconclusive and contradictory. The earliest study by Heunemann \& Turner (1942) compared weighed records of children's food intake with diet histories where food intakes were quantified with the aid of wax food models. The lack of agreement between the two methods was attributed to the inability of the children to accurately estimate the quantities of food reported in the diet histories. Conversely, Chattaway et al. (1946) showed that children aged $8-15$ years were able to estimate food quantity to within $\pm 10 \%$ of the amounts actually eaten, suggesting that children could quantify their food intake with reasonable accuracy. Nevertheless, subsequent studies appear to support the earlier finding that children do experience problems in reporting food quantities, even though these studies neglected to report fully the quantification tools used, or the magnitude of the errors which were incurred (Meredith et al. 1951; Young et al. 1952).

Overall, in the majority of studies which have used quantification tools such as household measures and graduated food models, scant attention has been paid to the efficacy, or otherwise, of such aids (Moore et al. 1967; Emmons \& Hayes, 1973; Frank et al. 1977; Carter et al. 1981, Jenner et al. 1989, Lytle at al. 1993). For example, children involved in a study by Van Horn et al. (1990) were expected to use two-dimensional models representing 'common food items, volume-related measuring tools, ... and diagrams for linear measurements', to quantify foods during a telephone-administered $24 \mathrm{~h}$ recall. Although it was concluded that serving sizes reported by children were likely to correspond with those observed by the parents, a close examination of the data shows that approximately one-quarter to half the children's estimates of portion sizes did not correspond with parental reports. It is not clear whether this lack of agreement was due to differences in the respective abilities of the parents and children to use abstract two-dimensional food models and/or to problems with memory retention and retrieval.

Unfortunately, the assumption that inclusion of any quantification tool will improve the estimation capabilities of children has not been verified. Estimating the amount of food consumed is a complex cognitive task, even for adults. It requires that children can recognize and describe quantities in terms of proportions or whole units, that they have an adequately developed concept of time to express food intake in terms such as frequency and averages, and finally, it assumes that the child can think abstractly about food while viewing generic food models of different volumes and dimensions or other tools such as food photographs. Furthermore, the problem is compounded by the fact that food frequencies and portion sizes of children are not constant over time and, in any case, it is most unlikely that they pay attention to frequencies and portion sizes when they are eating. It is not surprising, therefore, that the tasks involved in food quantification will be beyond the intellectual capacities of many children. 
Training in portion size estimation is known to improve the accuracy of dietary self-reporting in adults, but there are few comparable data in children. In adults the ability to estimate portion size of food eaten appears to be affected by the food type, the quantification aid(s) used and consistency of subject's perceptions and estimation skills. Only a few studies have examined these issues in children. Achterberg et al. (1991) trained a group of 8- and 9-year-old children in the use of three-dimensional portion-size instruments such as graduated bowls and cups of three sizes, but subsequently used a two-dimensional aid when the children recalled their food intake by $24 \mathrm{~h}$ recall. No information was provided on the agreement between the quantities of food reported by the children or the parents who observed their intakes. It is impossible, therefore, to attribute whether estimation of food intake was facilitated or hampered by the use of such an aid. In the most rigorous assessment to date, Weber et al. (1999) investigated the effect of a 45 min portion size estimation training exercise on improving the accuracy of estimated food portions in children aged 9-10 years. The training did result in significant improvements in ability to quantify foods, with the greatest improvements shown for solid foods estimated by dimensions and cups, and for liquids estimated by volume (cups), or by reading package labels. Amorphous foods were estimated least accurately both before and after training. Nevertheless, despite the considerable improvements in estimation capability, the error for several foods remained $>100 \%$ of the true quantity, indicating that more than one training session would be required to further improve reporting accuracy.

In conclusion, new methods for estimating portion sizes that are sensitive to the cognitive abilities of children are required. Until then, it must not be assumed that inclusion of any quantification tool will, by definition, assist children to estimate portion sizes. It may merely confuse children at best, or exacerbate the problem at worst.

\section{How children remember}

Dietary surveys based on recall ultimately rely on memory, which is subject to a variety of errors. However, while the importance of good memory is acknowledged, it is unlikely that many researchers fully appreciate the complexity of the task, for both respondent and observer, of remembering food-related information. The cognitive processes involved during dietary recall are complex, and involve understanding what information is being asked for, and searching for and evaluating the retrieved information before providing an answer. Errors can arise at any of these stages, either because the respondent is unable to complete the cognitive tasks involved, or because they have been hindered from doing so by inappropriate cues on the part of the observer. Clearly, understanding how children retain, retrieve and recall dietary information is important, not only for identifying the limits of accuracy of unassisted recall, but also to guide the development of strategies for enhancing accuracy of recall. To date, cognitive aspects of dietary recall have mainly focused on long-term dietary recalls of adults (Smith et al. 1991). The results emphasize the difficulties involved and demonstrate that the recall of food intake relies more on general rather than specific knowledge about habitual food intakes. Not surprisingly, recall errors increase as a function of time.

The limited research on children's recall of food intake also shows that considerable error can occur. These errors include both under-reporting (missing foods) and overreporting (phantom foods; Meredith et al. 1951; Samuelson, 1970; Emmons \& Hayes, 1973; Baranowski et al. 1986; Simons-Morton et al. 1990; Crawford et al. 1994; Domel et al. 1994b), and incorrect identification of foods because of a lower level of knowledge of foods and their preparation (Meredith et al. 1951; Samuelson, 1970; Emmons \& Hayes, 1973). Other factors which may hinder recall accuracy include: information overload, whereby there is an increased tendency to under-report as the number of foods eaten at a meal or overall eating frequency increases (Meredith et al. 1951; Baranowski et al. 1986); prevailing distractions (Baranowski et al. 1986); salience of the food items in the diet, such that main course items may be easier to remember than secondary items (Emmons \& Hayes, 1973), or common foods are more easily recalled than less-common foods.

A major limitation of many of the studies investigating the accuracy of recall in children is that they were mainly concerned with short-term recall (usually within $2 \mathrm{~h}$ of eating) of the meal, which was usually lunch. This factor suggests that some of the observed errors may have less to do with memory decay than they are to inattention. Errors in dietary recall attributable to memory decay are probably those that involve failure to report a percentage of foods eaten as a function of time and/or the developmental stage of the child. Clearly, there are limits to what children can remember, but to date little is known about the cognitive constraints on their ability to retain and retrieve dietary information.

In an attempt to address some of these issues a cognitive perspective on children's self-report of food intake, which is designed to enhance the accuracy of their reporting, has been proposed by Baranowski \& Domel (1994). The model, consisting of a sensory register, short-term memory and long-term memory can be applied to categorize errors in children's dietary reporting as due to attention, perception, organization, retention, retrieval or response formulation. Of key concern in applying this model is the need to understand how food-related information is organized in memory and subsequently retrieved in a dietary recall. This knowledge in turn may help inform the development of strategies such as changing the design of questionnaires to make them more age-sensitive and comprehensible, in combination with interview probing strategies and memory aids which may help to minimize errors at each stage in the cognitive process used in dietary recall.

In preliminary testing of the model, Domel et al. (1994b) have shown that the most usual retrieval-mechanism categories employed by children were: visual imagery (appearance of the food: colour, shape, consistency); usual practice (familiarity with eating the food previously); behaviour chaining (association or linking of food(s) to other food items or activities during the meal or day); preference (like, favourite food). Furthermore, the most accurate reports of food intake were elicited when children were prompted in a non-integrated interview protocol, i.e. when children reported retrospectively how they had 
remembered eating the foods they had just recalled, rather than trying to remember what they had eaten concurrently with recall of food intake. Subsequent studies have led to the validation of a consensus set of retrieval categories that could be used as cues to help children remember what they have eaten (Domel Baxter et al. 1997). Further research is obviously required to refine the model and address many unresolved issues such as the impact of time and lessexperimentally-controlled conditions on retention and retrieval responses. Nevertheless, the insights gained from cognitive psychology about how food-related information is stored, retrieved and recalled by children are encouraging and emphasize that exploration and application of perspectives from the behavioural sciences are necessary if the unassisted recall of dietary information by children is to be improved.

\section{Variability and tracking of nutrient intake}

\section{Variability in nutrient intake}

Some of the physiological processes that lead to diet-related diseases such as diabetes, obesity and cardiovascular disease in adulthood have their antecedents in childhood diet (Lauer et al. 1988; Must et al. 1992; Nieto et al. 1992; Wattigney et al. 1995; Srinivasan et al. 1996; Dietz, 1998). Thus, in epidemiological investigations of diet-health relationships in children and adolescents, accurate estimates of the intake of specific nutrients is vital in order to correctly rank or classify subjects in the distribution of intakes (tertiles, quartiles, quintiles etc.).

The ability of a dietary assessment to rank subjects depends on the ratio of within-:between-subject variances (variance ratio) in nutrient intake; the larger the ratio the more days of recording that are required to rank subjects correctly. The number of days of records or recalls required for distribution analysis has been examined by a number of authors (Beaton et al. 1979; Sempos et al. 1985; Marr \& Heady, 1986; Nelson et al. 1989; Hartman et al. 1990; Miller et al. 1991; Borrelli et al. 1992; Tarasuk \& Beaton, 1992), but only a few of these studies have addressed the issue in children and adolescents (Farris et al. 1985a,b; Nelson et al. 1989; Miller et al. 1991).

Without doubt the most striking finding in studies of children's nutrient intakes is that the variance ratio for most nutrients is much greater than it is for adults (Nelson et al. 1989; Miller et al. 1991). In younger children ( $\leq 4$ years old), because of the relatively low variance ratios, $7 \mathrm{~d}$ of records are probably adequate for ranking subjects for energy and most nutrients. This time period is substantiated by Birch et al. (1991) who examined the intra-individual variability in energy intake of children aged 2-5 years over $6 \mathrm{~d}$. In contrast to the mean $\mathrm{CV}$ of $33.6 \%$ for each child's EI at individual meals, the mean $\mathrm{CV}$ for each child's total daily EI was only $10.4 \%$. Thus, within-subject daily EI is relatively constant because children adjust their EI at successive meals.

In contrast, the variance ratios for older children and adolescents (5-17 years old) are, in general, approximately twice that observed in adults. Consistently higher values are observed in females, implying that in dietary surveys that include both males and females, males will be ranked more accurately for most nutrients for a given study period. Overall, the variability in intake is lowest for the nutrients that are eaten regularly in the diet and highest for the nutrients that are eaten in large amounts only occasionally, e.g. $\mathrm{Cu}$, carotene, retinol, vitamin $\mathrm{B}_{12}$, vitamin $\mathrm{E}$, polyunsaturated fatty acids and cholesterol. Vitamin intakes are the most variable, often requiring $\geq 20 \mathrm{~d}$ of records to capture habitual intake, particularly in girls.

The greater variability in nutrient intake seen in children and adolescents compared with adults has a number of important implications for the design and interpretation of dietary surveys in these age-groups.

First, they emphasize the vital importance of obtaining sufficient data for each subject to increase confidence in the ability to rank them. Second, these findings have been based, at least until recently, on the assumption that dietary data represent valid measures of habitual food intake. However, the recognition that self-reported dietary intakes, particularly in adolescents, are likely to be biased, mainly in the direction of under-reporting (Bandini et al. 1990, 1997; Livingstone et al. 1992; Bratteby et al. 1998), has implications for interpreting dietary surveys. Since underand over-reported intakes will extend the range of reported intakes, the ranking of these subjects into the extremes of the distribution may be invalid and result in biased conclusions. There is evidence that the range of 'habitual' energy expenditure is narrower than the range of reported EI. The total between-subject variation in 574 measurements of total energy expenditure (TEE) by the doublylabelled-water method (including 163 children and adolescents) from seventy-four studies was $15.4 \%$ (Black et al. 1996). However, in studies with repeated measurements by the doubly-labelled-water method the true between-subject variation may be approximately $12 \%$ (Black, 2000a). If this value represents the range of 'habitual' energy expenditure, then it must also represent the range of 'habitual' EI. However, dietary studies on children and adolescents typically report a total between-subject variation in EI of approximately $20 \%$, and even higher. This finding suggests that over- and under-reporting substantially extend the range of reported intakes beyond 'habitual' intakes. The effect of this factor could be to give a false impression of the ability to rank subjects, simply because the extreme values of a population distribution may reflect under- and over-reporting rather than true high or low intakes. The extent to which the observed high variability in the nutrient intake of children and adolescents can be attributed to bias in dietary reporting remains to be established.

Finally, the finding that prolonged recording may be required to characterize the intakes of many nutrients has major implications for the choice of survey instrument and the design of surveys. Clearly, ranking of children and adolescents based on only $7 \mathrm{~d}$ of records or recalls will be grossly inaccurate. On the one hand, this factor calls into question the feasibility of using intrusive and burdensome methods such as weighed or estimated dietary records (whose validity has, in any case, been questioned in older children and adolescents) or recalls, even if splitting the required recording period into sections was entertained. 
On the other hand, the application of food-frequency questionnaires (FFQ) or diet histories must be carefully evaluated, given the numerous problems in their application such as retrieval of dietary information from memory, conceptualization skills and portion size estimation.

\section{Tracking of nutrient intakes}

Tracking has been defined as the maintenance of relative position in rank over time (Kelder et al. 1994). Although several studies have reported that certain haematological variables track well from childhood into adulthood (Lauer et al. 1988; Webber et al. 1991; Porkka et al. 1994; Raitakari et al. 1994), data on the extent of tracking of nutrient intakes are inconclusive. Moderate to good tracking of some, but not all, nutrients has been observed in youngerage children (Stein et al. 1991; Singer et al. 1995). However, this finding is perhaps not surprising, since food intakes were likely to have been supervised, controlled and reported mostly by parents and/or caregivers.

In contrast, evidence for the phenomenon of nutrient tracking in older children and adolescents is inconsistent. For example, Boulton et al. (1995) assessed the tracking of dietary energy, fat and $\mathrm{Ca}$ in an Australian cohort from the age of 1 year to 15 years. The $\mathrm{Ca}$ intakes of the boys remained relatively consistent over time, and children who were 'big eaters' at a young age, remained so. However, those children who had reported lower EI at younger ages became more evenly spread across the distribution of intakes over time. On the other hand, when $\mathrm{Ca}$ intakes in Dutch males and females were assessed over a 12-year period, the tracking was 'not sufficiently strong' to identify subjects who were likely to have inadequate $\mathrm{Ca}$ intakes in adulthood (Welten et al. 1997). Tracking coefficients obtained in the same cohort for energy, protein, carbohydrate and fat were also slight to fair, suggesting poor maintenance in rank over time (Twisk et al. 1997).

To date, there have been few studies of the tracking of nutrient intakes within the adolescent period. In Northern Ireland, The Young Hearts Project (a longitudinal study of diet and lifestyle in children and adolescents; Robson et al. 2000) has attempted to assess the extent of tracking of energy and nutrient intakes, assessed by diet history, in subjects at 12 years of age and at follow-up 3 years later. Daily EI or nutrient intakes were considered to track well over time if 12-year-old subjects with 'low' (lowest $25 \%$ ), 'medium' (middle $50 \%$ ) or 'high' (highest $25 \%$ ) intakes maintained their ranking when assessed at age 15 years. Overall, tracking of EI and nutrient intakes in this study was only slight to fair, suggesting substantial drift of subjects between classes of intake over time. For example, $46 \%$ of boys who reported EI in the lowest intake category at age 12 years moved into the medium intake category when assessed at 15 years. Furthermore, $16 \%$ of the cohort moved from the lowest category for EI into the highest category.

There are several possible methodological explanations for the relatively low tracking observed in the Young Hearts cohort. First, the data may simply confirm that adolescence is associated with rapidly changing, and erratic, patterns of nutrient intake. Second, it is conceivable that the diet history is not a suitably robust tool for assessing tracking of nutrient intakes in a cohort of this nature. It is entirely possible that the levels of cooperation and motivation required to comply fully with a complex and lengthy interview could have led to substantial reporting error at both time points. However, it is debatable whether a method such as the weighed dietary record would fare any better, given the bias to underreporting which has been observed (Bandini et al. 1990, 1997; Livingstone et al. 1992; Bratteby et al. 1998). In effect, it is possible that the measurement error associated with assessing dietary habits in this age-group may be so great that it is unlikely that tracking could be detected.

\section{Validation of dietary intakes}

Validation studies

Until the late 1980s most dietary survey methods designed to measure habitual intake were rarely subject to independent validation. Consequently, most studies of dietary intake in children and adolescents were firmly based on the assumption that the methods were valid and provided measures of habitual intake. However, during this decade validation studies using TEE estimated by the doublylabelled-water method to assess the accuracy of EI reporting in children and adolescents indicate that much of the data are prone to bias, mostly through under-reporting.

Use of doubly-labelled water as a biomarker of EI is based on the assumption of energy balance; if body weight is stable, EI and TEE are equivalent. During growth and development children are normally in positive energy balance, but even then energy accretion is only about 1-2\% EI.

The validation studies of food intake in children and adolescents (Table 2) can be criticized because the EI of only small numbers of subjects in various age-groups were assessed. Moreover, most of the studies have been concerned with validating the results of either weighed or estimated records. Only one study has compared the accuracy of EI reporting by two methods (diet history and weighed dietary record) simultaneously in the same subjects (Livingstone et al. 1992). Nevertheless, taken together the studies do indicate that mis-reporting of EI in these groups is highly probable. Furthermore, the pattern of mis-reporting is not uniform across age-groups, and is influenced by weight status and the dietary survey method used.

Effect of age on validity. Age is clearly an important variable that affects compliance in dietary reporting. The overall trend towards an increase in energy under-reporting with increasing age has several possible explanations. In younger children the overall control of food intake and responsibility for reporting is likely to be a shared task between parents and other adults such as childminders. It is also likely that preschool children in particular have much less unsupervised access to supplementary sources of food both in- and out-of-home. In slightly older children (7-10 year olds), who probably have less supervision of their food intake out-of-home, the novelty and curiosity of recording food intake may help to sustain the levels of enthusiasm needed to comply fully with the reporting process. In adolescence, however, the onus for dietary reporting shifts to the subjects themselves, while at the same 
Table 2. Total energy expenditure (TEE) as measured by the doubly-labelled-water method compared with self-reported energy intake (EI) in children and adolescents

(Mean values and standard deviations)

\begin{tabular}{|c|c|c|c|c|c|c|c|c|c|c|}
\hline \multirow[b]{2}{*}{ Authors } & \multirow[b]{2}{*}{ Age (years) } & \multirow[b]{2}{*}{ Sex } & \multirow[b]{2}{*}{$n$} & \multirow{2}{*}{$\begin{array}{l}\text { Dietary } \\
\text { method }^{*}\end{array}$} & \multicolumn{2}{|c|}{$\mathrm{El}(\mathrm{MJ} / \mathrm{d})$} & \multicolumn{2}{|c|}{ TEE $(\mathrm{MJ} / \mathrm{d})$} & \multicolumn{2}{|c|}{ El: TEE } \\
\hline & & & & & Mean & SD & Mean & SD & Mean & SD \\
\hline Davies et al. (1994) & $1.5-4.5$ & $\mathrm{M}+\mathrm{F}$ & 81 & $4 \mathrm{~d}$ WDR & $4 \cdot 77$ & $0 \cdot 84$ & 4.93 & 0.99 & 0.97 & - \\
\hline Livingstone et al. (1992) & $3-5$ & $\mathrm{M}+\mathrm{F}$ & 20 & $\mathrm{DH}$ & $6 \cdot 29$ & $0 \cdot 71$ & $5 \cdot 76$ & $1 \cdot 12$ & $1 \cdot 12$ & $0 \cdot 19$ \\
\hline Kaskoun et al. (1994) & $4-7$ & $\mathrm{M}+\mathrm{F}$ & 45 & FFQ & $9 \cdot 12$ & $2 \cdot 28$ & $5 \cdot 74$ & $1 \cdot 13$ & 1.59 & - \\
\hline Johnson et al. (1996) & $4-7$ & $M+F$ & 24 & $\begin{array}{l}\text { Three } 24 \mathrm{~h} \\
\text { recalls }\end{array}$ & $6 \cdot 47$ & $1 \cdot 81$ & $6 \cdot 70$ & $2 \cdot 05$ & 0.97 & - \\
\hline \multirow{5}{*}{$\begin{array}{l}\text { MBE Livingstone } \\
\text { (unpublished results) }\end{array}$} & 6 & $\mathrm{M}+\mathrm{F}$ & 50 & $7 \mathrm{~d}$ WDR & & & & & & \\
\hline & $\begin{array}{c}(\mathrm{LR}) \\
6\end{array}$ & $\mathrm{M}+\mathrm{F}$ & 50 & $7 \mathrm{~d}$ WDR & $7 \cdot 03$ & $1 \cdot 26$ & $7 \cdot 22$ & $1 \cdot 15$ & 0.98 & $0 \cdot 17$ \\
\hline & $(\mathrm{HR})$ & & & & $7 \cdot 30$ & 1.49 & $7 \cdot 74$ & $1 \cdot 18$ & 0.95 & $0 \cdot 19$ \\
\hline & 6 & $\mathrm{M}+\mathrm{F}$ & 14 & $7 \mathrm{~d}$ WDR & & & & & & \\
\hline & (obese) & & & & $7 \cdot 55$ & 1.67 & $8 \cdot 77$ & $1 \cdot 11$ & 0.86 & $0 \cdot 16$ \\
\hline \multirow[t]{2}{*}{ Livingstone et al. (1992) } & 7-9 & $\mathrm{M}+\mathrm{F}$ & 24 & $\mathrm{DH}$ & $8 \cdot 88$ & 1.45 & $8 \cdot 20$ & 1.42 & $1 \cdot 10$ & $0 \cdot 16$ \\
\hline & $7-9$ & $\mathrm{M}+\mathrm{F}$ & 24 & $7 \mathrm{~d}$ WDR & $8 \cdot 32$ & $1 \cdot 77$ & $8 \cdot 20$ & 1.42 & 1.03 & 0.22 \\
\hline \multirow[t]{4}{*}{ Bandini et al. (1997) } & 8 & $\mathrm{M}+\mathrm{F}$ & 14 & $7 \mathrm{~d}$ EDR & - & - & - & - & 0.97 & 0.23 \\
\hline & 9 & $\mathrm{M}+\mathrm{F}$ & 40 & $7 d$ EDR & - & - & - & - & 0.95 & $0 \cdot 18$ \\
\hline & 10 & $\mathrm{M}+\mathrm{F}$ & 33 & $7 d$ EDR & - & - & - & - & 0.84 & 0.23 \\
\hline & 11 & $\mathrm{M}+\mathrm{F}$ & 19 & $7 d$ EDR & - & - & - & - & 0.81 & $0 \cdot 16$ \\
\hline \multirow{4}{*}{$\begin{array}{l}\text { Champagne et al. } \\
\text { (1998) }\end{array}$} & 9 & $\mathrm{M}+\mathrm{F}$ & 7 & $8 d$ EDR & $7 \cdot 58$ & 0.50 & $9 \cdot 30$ & 0.48 & 0.82 & - \\
\hline & 10 & $\mathrm{M}+\mathrm{F}$ & 81 & $8 d$ EDR & $7 \cdot 37$ & $0 \cdot 15$ & 9.51 & 0.14 & 0.77 & - \\
\hline & 11 & $\mathrm{M}+\mathrm{F}$ & 21 & $8 d$ EDR & $10 \cdot 10$ & 0.28 & $7 \cdot 87$ & 0.29 & 0.78 & - \\
\hline & 12 & $\mathrm{M}+\mathrm{F}$ & 9 & $8 d$ EDR & $10 \cdot 99$ & 0.43 & $7 \cdot 07$ & 0.45 & 0.64 & - \\
\hline \multirow[t]{2}{*}{ Livingstone et al. (1992) } & 12 & $\mathrm{M}+\mathrm{F}$ & 12 & $\mathrm{DH}$ & 11.96 & $2 \cdot 04$ & $10 \cdot 54$ & $1 \cdot 10$ & $1 \cdot 14$ & $0 \cdot 17$ \\
\hline & 12 & $\mathrm{M}+\mathrm{F}$ & 12 & $7 \mathrm{~d}$ WDR & $9 \cdot 36$ & 1.54 & $10 \cdot 54$ & $1 \cdot 10$ & 0.89 & $0 \cdot 12$ \\
\hline \multirow[t]{2}{*}{ Bandini et al. (1990) } & $12-18$ & $\mathrm{M}+\mathrm{F}$ & 28 (lean) & $14 \mathrm{~d}$ EDR & $9 \cdot 17$ & $2 \cdot 59$ & 11.53 & $2 \cdot 49$ & 0.81 & $0 \cdot 19$ \\
\hline & $12-18$ & $\mathrm{M}+\mathrm{F}$ & 27 (obese) & $14 \mathrm{~d}$ EDR & $8 \cdot 10$ & 3.02 & $14 \cdot 18$ & 2.56 & 0.59 & 0.24 \\
\hline Bandini et al. (1997) & $12-16$ & $\mathrm{M}+\mathrm{F}$ & 14 & $7 \mathrm{~d}$ EDR & - & - & - & - & 0.78 & $0 \cdot 17$ \\
\hline \multirow[t]{2}{*}{ Livingstone et al. (1992) } & $15-18$ & $\mathrm{M}+\mathrm{F}$ & 22 & $\mathrm{DH}$ & $12 \cdot 17$ & $3 \cdot 18$ & $12 \cdot 52$ & $3 \cdot 48$ & $1 \cdot 00$ & 0.21 \\
\hline & $15-18$ & $\mathrm{M}+\mathrm{F}$ & 22 & $7 \mathrm{~d}$ WDR & $9 \cdot 17$ & $2 \cdot 89$ & 12.52 & $3 \cdot 48$ & 0.76 & $0 \cdot 21$ \\
\hline \multirow[t]{2}{*}{ Bratteby et al. (1998) } & 15 & M & 25 & $7 \mathrm{~d}$ WDR & 11.40 & $2 \cdot 71$ & $13 \cdot 82$ & 1.90 & 0.82 & 0.18 \\
\hline & & $\mathrm{F}$ & 25 & $7 \mathrm{~d}$ WDR & $8 \cdot 28$ & 1.88 & $10 \cdot 70$ & 1.59 & 0.78 & $0 \cdot 16$ \\
\hline
\end{tabular}

WDR, weighed dietary record; EDR, estimated dietary record; $\mathrm{DH}$, diet history; FFQ, food-frequency questionnaire; LR, low risk of obesity (based on parental weight status); HR, high risk of obesity.

time there is a fall off in levels of interest in reporting food intakes. Consequently, the additional demands on recording imposed by increased energy requirements, unstructured eating patterns and a significant degree of out-of-home eating may be potent factors leading to loss of motivation, forgetfulness and ultimately reporting accuracy. Furthermore, these factors may be compounded by an exaggerated concern about body shape and image resulting in conscious or subconscious inhibition of eating.

Effect of obesity on validity. In common with obese adults (Prentice et al. 1986), obese adolescents (Bandini et al. 1990) and children (Champagne et al. 1998; MBE Livingstone, unpublished results) under-report EI significantly more than their non-obese counterparts. The extent of mis-reporting in subjects is also age-related, since up to 40 $\%$ of EI in obese adolescents may go unrecorded (Bandini et al. 1990) compared with $25 \%$ in 10 year olds (Champagne et al. 1998) and $14 \%$ in 6 year olds (MBE Livingstone, unpublished results). Even in a normal-weight adolescent population, Livingstone et al. (1992) and Bratteby et al. (1998) have observed a positive association between underestimation of food intake and a tendency towards increased body fatness and overweight.
The cause of the biased reporting of food intake in obese children and adolescents is unclear, but probably shares some of, or all, the same features that have been associated with mis-reporting in obese adults. These features include a wilful failure to record because it is time-consuming and inconvenient, a conscious desire to misrepresent a lower EI, subconscious memory lapses across all or selected dietary items such as snacks, and conscious dieting resulting in accurate, but nonetheless, unrepresentative food intakes. In addition, given the exaggerated preoccupation with body weight and image that is pervasive in adolescents, particularly girls, it is conceivable that obese teenagers may feel even more stigmatized about their fatness than obese adults.

In younger children, where parents are acting as surrogate respondents of children's food intake, the influence of parental adiposity on reporting accuracy is inconsistent. Parental obesity status has not been found to undermine the dietary intake data of lean children (Johnson et al. 1996; Bandini et al. 1997; MBE Livingstone, unpublished results), but a bias towards underestimation of food intakes of obese 6-7-year-old children who have at least one obese parent has been observed (MBE Livingstone, unpublished results). Clearly, the impact of obesity on reporting accuracy in these 
groups is complex. The magnitude of mis-reporting is agerelated and, in young children especially, may be affected by parental adiposity.

Although under-reporting is not inevitable in these groups, nevertheless obesity, dieting and weight consciousness have been identified as having the most frequent and consistent associations with mis-reporting. Researchers need to be alert, therefore, to the real probability of mis-reporting in these groups, either by the subjects themselves and/or by obese or weight-conscious parents who report their children's food intake.

Effects of the dietary survey technique. It is well recognized that the imposition of a particular survey technique may induce method-specific behavioural alterations in actual and reported food intake of adults (Black et al. 1993). This factor has also been verified in children and adolescents.

Diet records, either weighed or estimated, have been shown to provide unbiased records of EI in lean subjects up to 9 years old (Livingstone et al. 1992; Davies et al. 1994; Bandini et al. 1997; MBE Livingstone, unpublished results). However, the studies of adolescents and younger adults unanimously show that EI by this method are underreported by approximately $20 \%$, with the greatest bias observed in older subjects (Livingstone et al. 1992; Bandini et al. 1997; Bratteby et al. 1998). Thus, while mean EI by weighed dietary record was underestimated by $14 \%$ $(P<0.01)$ in 12 year olds, in $15-18$ year olds the magnitude of underestimation had increased to $24 \% \quad(P<0.01$; Livingstone et al. 1992). Using $14 \mathrm{~d}$ estimated dietary records, Bandini et al. (1990) also showed a remarkably similar level of under-reporting, with the negative bias being particular pronounced in obese subjects. After adjustment for changes in body composition, mean estimated EI were 80 (SD 23) \% (non obese) and 54 (SD 32) \% (obese) of the corresponding energy expenditure. It appears, therefore, that the magnitude of under-reporting is independent of the use of direct weighing or household measures as quantification tools.

In contrast, the diet history methodology apparently overcomes the age-related bias which is present in reporting by diet records. In the only study to date to examine reporting validity by the diet history (Livingstone et al. 1992), EI were overestimated in 3-, 5-, 7- and 9-year-olds but were accurate in 15- and 18-year-olds. Overall, mean EI by diet history were biased towards overestimation $(+8 \%)$. However, while this factor may be taken as establishing proof of primacy of the diet history methodology over diet records, the diet history data lacked precision at the individual level, with $35 \%$ of the results by diet history outside the $95 \%$ CI that assume a valid measure of habitual intake.

Unfortunately, there has also been limited assessment of the validity of $24 \mathrm{~h}$ recalls (Johnson et al. 1996) and the FFQ (Kaskoun et al. 1994), and then only in 4-7 year olds, which makes it difficult to generalize about the results. On a group basis, multiple $24 \mathrm{~h}$ recalls have been found to reflect EI accurately, but were not precise enough at an individual level (Johnson et al. 1996). However, the degree of mis-reporting in this age-group was not influenced by gender, age and body fatness of the children. In marked contrast, the application of FFQ in children of the same age resulted in a significant overestimation of EI by $53 \%$ (Kaskoun et al. 1994). One of the most likely explanations for the bias was the estimation of portion sizes based on typical adult servings.

In summary, these validation studies suggest that the diet record and $24 \mathrm{~h}$ recalls, and to a lesser extent the diet history, may provide more accurate group estimates of EI in younger age-groups. With increasing age, however, the reverse appears to occur with the diet history, demonstrating better validity, at least at the group level. However, the small number of studies to date preclude any firm conclusion about the advocacy of one method over another.

Subject-specific response in dietary reporting. It has long been recognized that food intake varies enormously from day to day within subjects, but it has been assumed that these extreme values are due to random chance variation in intake, and that with repeat measurements the extreme values would balance out to provide a valid measure of mean intake. However, it is conceivable that a subject who has under-reported dietary intake on one occasion will also under-report on a second occasion; in which case, the bias cannot be eliminated by repeated measurements. It has also been suggested that estimates of intake can be improved by administering two different dietary assessment instruments. This approach recognizes that there are large errors in all techniques, but assumes that the sources of error are independent in different methods.

This latter assumption has not been borne out in children and adolescents when EI was assessed simultaneously by weighed dietary record and diet history, and validated by the doubly-labelled-water method (Livingstone et al. 1992). There was clear evidence of a subject-specific response, such that subjects who under-reported by the weighed dietary record also did so by the diet history (Fig. 1). The strongest influence on EI:energy expenditure was the dietary assessment method $(P<0.0001)$, with the weighed

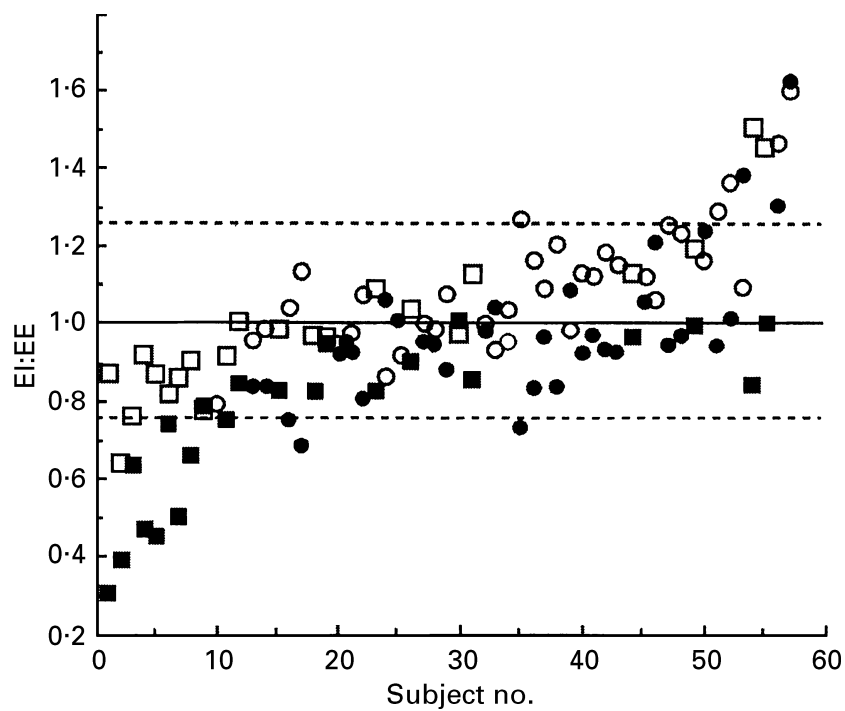

Fig. 1. Energy intake:energy expenditure (El:EE) values for $7 d$

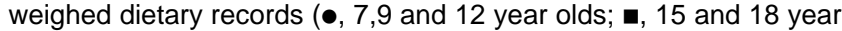
olds) and diet history ( $\bigcirc, 7,9$ and 12 year olds; $\square, 15$ and 18 year olds) in children and adolescents ( $n$ 60). (-) Expected value of 1.0 ; (-----), $95 \% \mathrm{Cl}$ of agreement between $\mathrm{EI}$ and $\mathrm{EE}$. (From AE Black, unpublished results.) 
dietary record showing a greater bias to under-reporting. The second-most-important influence was the age of the subject $(P<0 \cdot 0001)$. Compared with the 7-, 9- and 12-yearolds, the 15- and 18-year-olds showed a marked bias to under-reporting and a stronger tendency for individuals to have a similar response to both methods. The effect of gender was small and not significant, with males just as likely to under-report as females. This finding of a subjectspecific response in dietary assessments implies that the assumption that repeated measures of dietary intake will eventually yield valid measures of habitual intake is not necessarily true. Under- and over-reported intakes will simply extend the range of reported intakes and, consequently, the ranking of these subjects into the extremes of the distribution may be invalid and result in biased conclusions.

\section{The detection of mis-reporting}

It is now widely accepted that mis-reporting is a major problem in dietary surveys, not just in adults, but also in children and adolescents. What children and adolescents say they eat is clearly not what they do eat. Consequently, their dietary data can no longer be accepted at face value, and all data should be subjected to critical examination for evidence of bias. Ideally, some means of independently validating dietary data should be built into all dietary studies of paediatric populations. The doubly-labelled-water method is too expensive and technically challenging to be used routinely to validate EI data. However, this method has provided the impetus to begin evaluating EI data by comparison with presumed energy requirements, expressed as physical activity levels (PAL; Black et al. 1991; Goldberg et al. 1991). Since the publication of these seminal papers, researchers who work in the field have used the cutoffs for assessing the likely validity of group and individual EI data. However, for a number of justifiable reasons at that time, a PAL of 1.55 (based on the Food and Agriculture Organization/World Health Organization/United Nations University (FAO/WHO/UNU; 1985) requirements for a sedentary lifestyle) was chosen as the yardstick to examine the validity of reported EI when expressed as EI:estimated or measured BMR. This PAL value is now acknowledged to be a conservative estimate, based on a subsequent review of 574 doubly-labelled-water measurements of TEE (Black et al. 1996).

Thus, while food intake data are now being scrutinized and interpreted much more critically, nevertheless, the underlying concepts are not always applied correctly. Common misinterpretations include: applying the cut-off calculated for a group to individual data; applying the cutoff for 'habitual' intake with that for a low intake obtained by chance; interpreting the given examples of cut-off values based on a PAL value of 1.55 as recommendations that can be applied universally; finally, application of cut-offs designed for screening the EI data of adults for the evaluation of the EI data of children and adolescents.

The effect of substituting the Goldberg et al. (1991) cut-off based on a yardstick PAL of 1.55 for the appropriate age- and gender-specific cut-offs for children (also based on an assumed light PAL) has recently been illustrated by
Kersting et al. (1998) on a data set of $6953 \mathrm{~d}$ weighed dietary records from German children and adolescents aged 1-18 years. Based on a blanket cut-off derived from a PAL of 1.55 , approximately $10 \%$ of the records were excluded as being implausible. The extent of mis-reporting varied by age, being lowest in the 1-5 year olds (approximately $2 \%$ ) and highest in the adolescent males $(11 \%)$ and females $(31 \%)$. Since the appropriate age- and sex-specific cut-offs for children and adolescents (Torun et al. 1996) are lower than the cut-off based on PAL 1.55, except in the older adolescent males aged 14-18 years, the overall effect of applying this cut-off was to reduce the exclusion rate to $6.5 \%$ in the total group, and to $20 \%$ in the adolescent females. The results of this study are salutary: use of cutoffs that were never designed to evaluate the EI of children and adolescents can distort a data set by 'overestimating' the extent of dietary mis-reporting. Thus, while the principles of the Goldberg et al. (1991) cut-offs still hold when assessing the EI of children and adolescents, appropriate age- and gender-specific cut-offs should always be applied in a paediatic population.

What factors should guide the choice of an appropriate PAL cut-off? One of the major limitations in using a single cut-off or EI:BMR based on a sedentary PAL value is that it will only determine the probable degree of overall bias in a data set, but it is of limited value for identifying underreporting at the individual level. Under-reporting occurs at all levels of TEE, and it has been estimated that use of this single cut-off will fail to identify about $50 \%$ of underreporters (Black, 1997). If this finding is applied to an adolescent population, this single cut-off could considerably underestimate the extent of under-reporting, given that as TEE in this group increases, the magnitude of reporting error also increases (Bandini et al. 1990, 1997; Livingstone et al. 1992).

The situation will be slightly improved if an appropriate higher mean age- and gender-specific PAL is used for groups that are more active. This procedure will better assist in identifying the presence or absence of bias in underreporting at both the group and the individual level. The specificity is improved still further if information on activity patterns is available to allow each subject to be assigned to a low, medium or high activity level, thereby enabling three different cut-offs for the identification of individual underreporters in each of the three bands of activity. The new estimates of energy requirements (expressed as PAL) for light, moderate and heavy physical activity in 1-18 yearolds which are proposed for a revision of the current FAO/WHO/UNU (1985) recommendations could be used for this purpose (Torun et al. 1996).

Finally, if detailed information on activity patterns can be obtained by questionnaires, activity diaries, or some more objective measure such as heart-rate monitoring, then subject-specific PAL could be used to validate the EI of each subject individually, in which case the Goldberg et al. (1991) cut-off becomes redundant. Given that this cut-off is limited by low sensitivity and poor specificity (Black, $2000 \mathrm{~b}$ ) this procedure is the ideal, but is only likely to be feasible in small-scale studies.

Although most attention to date has focused on the issue of under-reporting, the possibility of systematic 
over-reporting cannot be excluded. At present, however, identification of its presence and magnitude in the EI data of children and adolescents is virtually impossible. The existing doubly-labelled-water data in these groups (Black et al. 1996) provide only limited information on which to define an appropriate PAL for calculating upper $95 \% \mathrm{CI}$ or cut-offs, and thus identify over-reporters. Caution should also be applied if using the age- and gender-specific PAL values for heavy habitual physical activity (Torun et al. 1996). In these proposals, only energy requirements for moderate physical activity were experimentally derived. The lower and upper ranges for light and heavy activity have been arbitrarily defined by $\mathrm{CV}$ of $\pm 12 \%$. Consequently, detection of the magnitude of over-reporting in children and adolescents will remain elusive until much more experimentally-derived data on TEE are available to calculate the upper CI.

In conclusion, the proper application of age- and genderspecific PAL levels based on a knowledge of the habitual physical activity pattern of subjects will provide some clues, albeit limited, to the magnitude of reporting bias and to those most likely to mis-report. Unfortunately, to date, few studies have examined their data sets in this way, but those that have, have provided some interesting insights into who under-reports and what is under-reported. Kersting et al. (1998), for example, have clearly identified that underreporting is a major problem in female adolescents and those children and adolescents with a higher BMI. Male adolescents were found to return diet records of acceptable validity, but whether this is real, or an artefact, due to screening based on an inappropriate PAL value, is not clear. The under-reporters in the adolescent group recorded fewer meals per $\mathrm{d}$ and a lower sugar intake (\% EI) than their non-under-reporting counterparts. It was speculated that this finding may be due to specific omissions of sweet and/or snack foods.

Finally, validation against indices of energy expenditure identifies only the bias in the reporting of EI. This factor raises key questions as to whether the diet is under-reported as a whole, or whether there is selective under-reporting of different foods leading to further bias in the reporting of nutrient intake. These issues have yet to be addressed in dietary studies of children and adolescents. Until they are, it may be appropriate when evaluating nutrient intake data to consider the reported intakes as minimum true intakes, while accepting that for some nutrients and some individuals an over-estimation will be made.

\section{Criteria for selecting a dietary survey method}

The choice of a dietary survey method for any population group depends on the objectives, the number and characteristics of the study population and the available resources. When children and adolescents are the target population, blending the method with respondent capability is paramount. However, even after 40 years of research, and a plethora of comparative studies, there are no universal criteria which can be applied when selecting data-collection methods suitable for studies of children and adolescents.

When selecting a dietary-assessment technique for studies in children and adolescents each method must be judged on its own merits, relative to the objectives of the study and the following general and age-specific criteria.

\section{General}

State the objectives, define the problem and recognize the limitations. Dietary surveys are often used to answer different kinds of questions simultaneously, e.g. meal patterns, food frequencies and intakes of energy and nutrients. When used for different purposes this approach almost certainly limits the validity of the survey instrument, aside from any issue of dietary mis-reporting. A clear concept of the objectives and good planning to achieve them will help to diminish errors.

The quality of dietary reporting decreases during the recording period. If recording or reporting is carried out more assiduously at the start of a multi-day record, the starting days should be evenly distributed across the days of the week (Perrson \& Carlgren, 1984; Berg et al. 1998). Similarly, in multiple recalls attention should be given to the risk of fatigue, boredom and/or training effects (Haraldsdóttir \& Hermansen, 1995). If not, the introduction of a systematic error with repeated measurements could seriously outweigh any advantages of repeated recalls.

Ensure impartiality of surrogate respondents. When surrogate respondents such as parents are questioned about children's food intake, inbuilt safeguards are needed to ensure impartial reporting, e.g. parents who report what they believe their child should eat, rather than what they actually do eat.

Include measures to evaluate the quality of dietary reporting. All dietary surveys of children and adolescents should routinely include measurements of height and weight (for estimation of body fatness and BMR), and assessment of physical activity to allow the selection of a PAL value appropriate for the age and gender of the subject. In older children and adolescents consideration should also be given to including assessments of body image, body shape preferences, social desirability and attitudes to food. While these measures cannot detect the magnitude of misreporting, they may assist in the identification of the sources of bias, and ultimately lead to better study designs and improved strategies for interpreting dietary data in these age-groups.

Previous training in portion size estimation is required. Visual estimation of the amounts of food consumed or wasted is difficult, even for adults. It demands that the subject has a clear mental image of food portions eaten, while viewing generic food models of different volumes or dimensions, household measures and/or other aids such as photographs. Portion size estimation can be improved by training, but a number of such sessions are likely to be required to achieve the level of effectiveness needed to increase overall accuracy (Yuhas et al. 1989; Weber et al. 1999). Inevitably, many surveys are subject to time constraints, and such training exercises may therefore be seen as superfluous. At the very least, serious consideration should be given to previous training in portion size estimation, even in group settings. If training is not feasible, researchers should at least reassure themselves that the quantification tool selected is compatible with the cognitive capabilities of the subjects concerned. 
Variability in nutrient intake has implications for study design. The within-subject variability relative to betweensubject variability in nutrient intake is much larger in children than in adults (Farris et al. 1985a,b; Nelson et al. 1989; Miller et al. 1991). Thus, if the aim of the study is to rank individuals in a group, it is most unlikely that $7 \mathrm{~d}$ of records or recalls will accurately classify them. For those nutrients that require an extended observation period, researchers need to be aware of the need either to obtain a sufficient number of records or recalls, or choose an appropriate alternative such as a diet history which is designed to measure habitual intake.

\section{Young children}

Assess the ability of parents to report their children's food intake. Until children have reached the developmental stage when they are aware of their food intake and can begin to conceptualize time (at approximately 7-8 years), the onus for dietary reporting falls on the parents. Given that parents are reliable reporters of their children's food intake only for food eaten at home (Klesges et al. 1987, 1988; Eck et al. 1989; Basch et al. 1990; Baranowski et al. 1991), and that many parents now work out-of-home, their ability to report food intake should not be assumed, but verified. Inevitably, others who care for the child, such as childminders, need to be included in the reporting process, but it is likely that they will approach the task with varying levels of motivation and interest. It is recommended that criteria for when not to use parents or other caregivers as surrogate respondents should be established at the outset of surveys on children younger than 7-8 years.

The ability of children to conceptualize the time frame used in dietary instruments e.g. $24 \mathrm{~h}, 1$ week, 1 month is not established, but assumed. It is vital that the ability of children to conceptualize the time periods being assessed is established at the outset of a survey. A young child's amorphous concept of the past, being 'before now' presents particular problems when they attempt to self-report the frequency of food consumption or recall food actually eaten. From about the age of 7-8 years there is a fairly rapid increase in the ability of children to self-report their food intake without parental assistance, but only for the immediate past and for no longer than the previous $24 \mathrm{~h}$. Even then, it is likely that children may just be old enough to cope with remembering weekday food intake, but not with the more irregular eating pattern associated with weekend days (Haraldsdóttir \& Hermansen, 1995). These findings, which have been endorsed by others (Emmons \& Hayes, 1973; Van Horn et al. 1990; Achterberg et al. 1991; Lytle et al. 1993), suggest that by the age of 8-10 years children can reliably report their food intake, often as reliably as their parents. Moreover, at a group level, repeated $24 \mathrm{~h}$ recalls in this age-group may be a feasible alternative to a diet history interview with parents (Haraldsdóttir \& Hermansen, 1995).

However, whether children younger than 10 years could give valid responses to a FFQ covering periods greater than $1 \mathrm{~d}$ is much more debatable because of their inability to conceptualize frequency, averaging etc. (Baranowski et al. 1986; Domel et al. 1994a).
In older children (>9-10 years), the child's ability to perform the tasks required often dictates the method used. In planning a dietary survey of young children, using the child as the only respondent has obvious practical advantages, particularly if schools are willing to co-operate in data collection. The literature, to date, suggests that children aged 8 years and over can reliably recall foods eaten in the recent past provided that the time period under investigation is not subject to irregular events and/or eating patterns. However, food recalls tap a child's memory and require the child to think abstractly about specific foods. At the same time, the recall may involve using generic food models of different volumes or dimensions, or other aids such as food photographs. Food records, on the other hand, require that children (in co-operation with parents) can write names of foods legibly, have an appropriate level of experience with food preparation, remember what is eaten out-of-home and, finally, are able to quantify food intake by direct weighing or estimation.

Aside from the resource implications, the decision about which method to select must be guided by the certainty that some children will not have the required cognitive, literacy and/or technical skills required to participate fully in either or both these methods. It is essential that the development stage of subjects is established before selecting a particular survey instrument.

The way in which children perceive, categorize and organize foods in memory could have major implications for later recall. It is likely that different children will perceive and classify foods in different ways, depending on their developmental level (Michela \& Contento, 1984), and that these perceptions and classifications may well be different from those used by investigators. Consequently, particular attention should be paid to including appropriate cues and prompts to aid memory retrieval, but which at the same time do not run the risk of eliciting socially-desirable responses. Undoubtedly, a major cause of mis-identification of food items by young children is their limited knowledge of food and food preparation (Meredith et al. 1951; Samuelson, 1970). Food lists or food pictures may act as memory prompts, but recognition problems could occur, either because foods actually eaten do not appear in these memory prompts, or because of over-identification, where commonly-consumed foods are recalled as being eaten, when in fact they are not. Recall errors are also likely to be reduced if children are encouraged to reconstruct the context in which the food is eaten (events, activities, people, meals), and the information is then used to cue what was eaten (Frank et al. 1977). Initial research into determining which retrieval responses children use for remembering items of food consumed has begun to provide better insight into this complex, but until now, little explored area (Baranowski \& Domel, 1994; Domel, 1997; Domel Baxter et al. 1997).

\section{Older children and adolescents}

Methods of dietary assessment that are perceived as less burdensome and time-consuming may improve reporting compliance Children aged 10-12 years can be reliable reporters of their food intake. Adolescents are capable of providing dietary data by all the usual methods but are often 
found to be less interested in participating than younger children. Under-reporting, particularly by older adolescents, may be a particular problem in studies using weighed or estimated records. If non-obese adolescents consistently under-estimate their EI by approximately $20 \%$ (Bandini et al. 1990, 1997; Livingstone et al. 1992; Bratteby et al. 1998) by these methods, then they may be particularly unsuitable for assessing the food intakes of teenagers. The greater food requirements of these subjects, in combination with unstructured eating patterns and a significant degree of out-of-home eating, suggest that the serious bias to underestimation by this method in this age-group may be due to a combination of forgetfulness and lack of compliance, caused by the irritation and boredom of having to record intakes on an almost hour-to-hour basis.

On the other hand, the apparent superiority of the diethistory method in overcoming the age-related bias in recording by the weighed dietary record needs to be evaluated carefully (Livingstone et al. 1992). The diet history is not a standardized technique, and despite good validity at the group level it is clearly prone to significant problems of precision at the individual level. Moreover, since it measures only memory and perception of usual diet, it is subjective and vulnerable to socially-desirable responding. Finally, the grazing eating pattern of many adolescents will inevitably pose a more complex and lengthy interview on subjects, and an increased burden on their attention and memory spans.

The alternatives to both these methods, the $24 \mathrm{~h}$ recall and FFQ, have the advantages of being less time-consuming, less intrusive and cheaper to administer, and therefore are potentially more likely to be acceptable to adolescents. However, given the extent of variability in food intake that has been observed in this group, multiple $24 \mathrm{~h}$ recalls will be required to estimate food intake at the individual level (Nelson et al. 1989; Miller et al. 1991). Recalls are also likely to share some of the problems associated with the diet history in relation to estimation of portion size, socialdesirability responding and retrieval of information from memory. The literature on the use of FFQ in children and adolescents has been sparse, subject only to relative validity checks and yielding inconsistent results that are difficult to interpret (Blom et al. 1989; Jenner et al. 1989; Frank et al. 1992; Gallagher et al. 1993; Hammond et al. 1993; Domel et al. 1994a; Rockett et al. 1995; Frost Andersen et al. 1995). In addition, little attention has focused on deciding what foods should be included in a FFQ for these age-groups. Until independent validation studies of the accuracy, or otherwise, of repeat $24 \mathrm{~h}$ recalls and FFQ are carried out, and the limits of their accuracy are defined in these age-groups, researchers should be cautious in their application.

Include measures of dietary restraint and body image. It is now well accepted that many normal-weight adolescents, especially girls, are dissatisfied with their weight and would like to be thinner (Nylander, 1971; Wardle \& Beales, 1986; Hill et al. 1994). Such dissatisfaction has been demonstrated in girls as young as 9 years of age, and it accelerates with age and sexual maturation (Kirkley \& Burge, 1989). The same trend has been observed in boys, but at a less-pronounced level (Wardle \& Marsland,
1990). Weight concerns are typically associated with attempts to restrict food intake. Since high levels of dietary restraint, whether real or apparent, are more than likely to constitute a source of bias in dietary surveys, it is important, where possible, to characterize subgroups most likely to mis-report their food intake. A number of instruments are available for assessing eating styles and attitudes, including the Dutch eating behaviour questionnaire (Van Strien et al. 1986), which has been used in children as young as 9 years old (Hill \& Robinson, 1991), and the children's eating attitude test (Garner et al. 1982; Maloney et al. 1988, 1989). Additional information on body esteem (Mendelson \& White, 1982), self-esteem (Coopersmith, 1967), body shape preferences (Fallon \& Rozin, 1985; Collins, 1991) and body shape attitudes (Hill \& Silver, 1995) can all be measured in children as young as 9 years old, and may serve as a useful adjunct in attempts to identify possible mis-reporting of food intake.

Modify probing, coding and reporting formats to reflect the eating patterns of adolescents. The characteristic dietary patterns of adolescents which include frequent snacking, fast foods, grazing and meal skipping suggest that breaking out of the conventional mind set of three meals is merited when eliciting dietary information from these subjects. In addition, the issue arises of whether foods should be coded as meals or snacks, or indeed, if it is instructive to evaluate food intakes in this way at all. The current eating patterns of adolescents suggest that it is now timely for food coding and interviewing techniques to be reassessed in order to permit more informed evaluation of the eating behaviour and food and nutrient intakes of this group.

\section{The Way Forward}

'Meal patterns and food choices are complex social and cultural phenomena. The measurement of food intake dietary assessment - is a complex social interaction between the investigator and the subject. The ultimate aim of dietary assessment, however, is to provide a number i.e. nutrient intake. This numerical outcome often leads the inexperienced to assume an inherent precision to the process that does not exist.' (Black, 1999).

These observations and thoughts encapsulate many of the problems that currently face nutritionists when carrying out dietary assessments, and at the same time provide some valuable clues for the way forward.

Most of the research in the last decade has focused on the validity of the dietary data of adult subjects. The advances during this time have led to an honest and widespread recognition of mis-reporting, more critical approaches to the analysis of dietary data, and preliminary pointers for the design of future studies, specifically to identify mis-reporting. At the same time, nutritionists have come to appreciate that exploration and application of creative approaches which embrace the concepts and techniques of the social sciences is necessary to both the process and outcome of dietary assessments. Finally, in recognition that human behaviour may be such that it may not be possible to improve reporting accuracy, the importance of appropriate statistical procedures in data handling and 
analysis that will allow for systematic bias is increasingly acknowledged.

To date, the validation studies of EI reporting in children and adolescents have also conclusively demonstrated the existence of mis-reporting, but unfortunately further progress in understanding the problem has been limited. While it is likely that some of the issues are similar to those observed in adults, nevertheless, when children and adolescents are the target population many specific respondent and observer considerations surface. This factor makes it imperative not to generalize from adult studies, but rather to focus attention on what are likely to be unique reporting issues in these groups. What research should be undertaken in order to improve the quality of dietary data obtained from children and adolescents in the future?

1. Definitive validation studies of all techniques, but particularly the diet history, $24 \mathrm{~h}$ recall and FFQ, across all ages in childhood and adolescence;

2. a more extensive database of assessments of TEE by the doubly-labelled-water method. At present it is virtually impossible to identify the presence and magnitude of over-reporting of EI data of children and adolescents. Rather than rely on arbitrarily-defined age- and gender-specific PAL values for very active lifestyles, as is currently the case, experimentally-derived PAL values would permit the definition of appropriate PAL values for calculating upper $95 \%$ CI or cut-offs. Thus, the presence of over-reporting could be identified with more confidence than at present;

3. development of improved techniques to identify under-reporters at the individual level. Patterns of underreporting in children and adolescents are not necessarily the same as in adults and need clarification. Ideally, costeffective and objective measures of physical activity are required to permit direct comparisons of EI and energy expenditure;

4. investigation of the issue of differential reporting of macronutrients, whether particular food types, meals or snack foods are more likely to be mis-reported, together with the reasons for doing so, need study;

5. identification and characterization of subgroups most likely to mis-report food intakes, together with the reasons for doing so, requires psychological assessments which are age sensitive. These assessments should be universally agreed and uniformly applied;

6. evaluation of non-response bias. The reasons for, and effects of, non-participation by children and adolescents should be studied to identify possible sources of bias and to assess the implications for the design, analysis and interpretation of results (Berg et al. 1998);

7. development of new and/or refinement of existing dietary survey methods that are sensitive to different ages, cognitive abilities and motivation levels. Data collection methods that are simple and not excessively timeconsuming for respondents are more likely to improve reporting compliance. At the same time, children and adolescents are increasingly computer literate; interactive multimedia and other computer technology could usefully be exploited for unobtrusive and non-intrusive dietary recording by children and adolescents (Cullen et al. 1998);
8. better understanding of the cognitive processes involved in dietary recall. Greater insight into what aspects of foods or eating experiences are retained in memory, how much is retrieved, and the influences on reporting ability will help not only to identify the limits of unassisted recall, but also to develop strategies to enhance the accuracy of their dietary self-reports;

9. improved methodology for estimating portion sizes. The ability of children and adolescents to estimate portion size needs to be improved by designing new methods which take account of their developmental levels. Until then, quantification of food and nutrient intakes will include a largely unknown component of error;

10. refinement of statistical techniques to account for systematic bias in paediatric populations. Statistical models need to be developed that will estimate the impact of systematic bias on estimates such as relative risk, variance ratios, or proportions of the population with inadequate intakes;

11. Examination and evaluation of the impact of random and systematic errors due to food composition data bases.

\section{References}

Achterberg C, Pugh MA, Collins S, Getty VM \& Shannon B (1991) Feasibility of telephone interviews to collect dietary recall information from children. Journal of the Canadian Dietetic Association 54, 226-228.

Bandini LG, Cyr H, Must A \& Dietz WH (1997) Validity of reported energy intake in preadolescent girls. American Journal of Clinical Nutrition 65, Suppl., 1138S-1141S.

Bandini LG, Schoeller DA, Cyr HN \& Dietz WH (1990) Validity of reported energy intake in obese and nonobese adolescents. American Journal of Clinical Nutrition 52, 421-425.

Baranowski T \& Domel SB (1994) A cognitive model of children's reporting of food intake. American Journal of Clinical Nutrition 59, Suppl., 212S-217S.

Baranowski T, Dworkin R, Henske JC, Clearman DR, Dunn JK, Nader PR \& Hooks PC (1986) The accuracy of children's selfreports of diet: Family Health Project. Journal of the American Dietetic Association 86, 1381-1385.

Baranowski T, Sprague D, Baranowski JH \& Harrison JA (1991) Accuracy of maternal dietary recall for preschool children. Journal of the American Dietetic Association 91, 669-674.

Basch CE, Shea S, Arliss R, Contento IR, Rips J, Gutin B, Irigoyen M \& Zybert P (1990) Validation of mothers' reports of dietary intake by four to seven year-old children. American Journal of Public Health 80, 1314-1317.

Beaton GH, Milner J, Corey P, McGuire V, Cousins M, Stewart E, Ramos M, Hewitt D, Grambsch PV, Kassim N \& Little JA (1979) Sources of variance in 24-hour dietary recall data: implications for nutrition study design and interpretation. American Journal of Clinical Nutrition 32, 2546-2559.

Berg C, Jonsson I, Conner MT \& Lissner L (1998) Sources of bias in a dietary survey of children. European Journal of Clinical Nutrition 52, 663-667.

Birch LL, Johnson SL, Andresen G, Peters JC \& Schulte MC (1991) The variability of young children's energy intake. New England Journal of Medicine 324, 232-235.

Black AE (1997) Under-reporting of energy intake at all levels of energy expenditure: evidence from doubly labelled water studies. Proceedings of the Nutrition Society 56, 121A

Black AE (1999) Dietary energy intake measurements: validations against energy expenditure. DPhil Thesis, University of Ulster. 
Black AE (2000a) Within- and between-subject variation in energy expenditure measured by the doubly labelled water technique: implications for validating reported dietary energy intake. European Journal of Clinical Nutrition (In the Press).

Black AE (2000b) The sensitivity and specificity of the Goldberg cut-off for EI : BMR for identifying diet records of poor validity. European Journal of Clinical Nutrition (In the Press).

Black AE, Coward WA, Cole TJ \& Prentice AM (1996) Human energy expenditure in affluent societies: an analysis of 574 doubly-labelled water measurements. European Journal of Clinical Nutrition 50, 72-92.

Black AE, Goldberg GR, Jebb SA, Livingstone MBE, Cole TJ \& Prentice AM (1991) Critical evaluation of energy intake data using fundamental principles of energy physiology: 2 . Evaluating the results of published surveys. European Journal of Clinical Nutrition 45, 583-599.

Black AE, Prentice AM, Goldberg GR, Jebb SA, Bingham SA, Livingstone MBE \& Coward WA (1993) Measurements of total energy expenditure provide insights into the validity of dietary measurements of energy intake. Journal of the American Dietetic Association 93, 572-579.

Blom L, Lundmark K, Dahlquist G \& Persson LA (1989) Estimating children's eating habits: validity of a questionnaire measuring food frequency compared to a 7-day record. Acta Paediatrica Scandinavica 78, 858-864.

Borrelli R, Simonetti MS \& Fidanza F (1992) Inter- and intraindividual variability in food intake of elderly people in Perugia. British Journal of Nutrition 68, 3-10.

Boulton TJC, Margarey AM \& Cockington RA (1995) Tracking of serum lipids and dietary energy, fat and calcium intake from 1 to 15 years. Acta Paediatrica 84, 1050-1055.

Bratteby L-E, Sandhagen B, Fan H, Enghardt H \& Samuelson G (1998) Total energy expenditure and physical activity as assessed by the doubly labeled water method in Swedish adolescents in whom energy intake was underestimated by 7-d diet records. American Journal of Clinical Nutrition 67, 905-911.

Carter RL, Sharbaugh CO \& Stapell CA (1981) Reliability and validity of the 24-hour recall. Journal of the American Dietetic Association 79, 542-547.

Champagne CM, Baker NB, DeLany JP, Harsha DW \& Bray GA (1998) Assessment of energy intake underreporting by doubly labeled water and observations on reported nutrient intakes in children. Journal of the American Dietetic Association 98, 426-433.

Chattaway FW, Happold FC \& Happold AM (1946) Nutrition of school-children in Leeds, winter 1943, and summer, 1944. British Medical Journal i, 429-435.

Collins ME (1991) Body figure perceptions and preferences among preadolescent children. International Journal of Eating Disorders 10, 199-208.

Coopersmith S (1967) The Antecedents of Self-esteem. San Francisco, CA: Freeman.

Crawford PB, Obarzanek E, Morrison J \& Sabry ZI (1994) Comparative advantage of 3-day food records over 24-hour recall and 5-day food frequency validated by observation of 9and 10-year-old girls. Journal of the American Dietetic Association 94, 626-630.

Cullen KW, Baranowski T \& Baranowski J (1998) Computer software design for children's recording of food intake. Journal of Nutrition Education 30, 405-409.

Davies PSW, Coward WA, Gregory J, White A \& Mills A (1994) Total energy expenditure and energy intake in the preschool child: a comparison. British Journal of Nutrition 72, 13-20.

Dietz WH (1998) Health consequences of obesity in youth: childhood predictors of adult disease. Pediatrics 101, $518-525$.
Domel Baxter S, Thompson WO, Davis HC \& Johnson MH (1997) 'How do you remember you ate...?': a Delphi technique study to identify retrieval categories from fourth-grade children. Journal of the American Dietetic Association 97, 31-36.

Domel SB (1997) Self-reports of diet: how children remember what they have eaten. American Journal of Clinical Nutrition 65, Suppl., 1148S-1152S.

Domel SB, Baranowski T, Davis H, Leonard SB, Riley P \& Baranowski J (1994a) Fruit and vegetable food frequencies by fourth and fifth grade students: validity and reliability. Journal of the American College of Nutrition 13, 33-39.

Domel SB, Thompson WO, Baranowski T \& Smith AF (1994b) How children remember what they have eaten. Journal of the American Dietetic Association 94, 1267-1272.

Eck LH, Klesges RC \& Hanson CL (1989) Recall of a child's intake from one meal: are parents accurate? Journal of the American Dietetic Association 89, 784-787.

Emmons L \& Hayes M (1973) Accuracy of 24-hr. recalls of young children. Journal of American Dietetic Association 62, 409-415.

Fallon AE \& Rozin P (1985) Sex differences in perceptions of desirable body shape. Journal of Abnormal Psychology 94, 102-105.

Farris RP, Cresanta JL, Frank GC, Webber LS \& Berenson GS (1985a) Dietary studies of children from a biracial population: intakes of carbohydrate and fiber in 10- and 13-year-olds. Journal of the American College of Nutrition 4, 421-435.

Farris RP, Cresanta JL, Webber LS, Frank GC \& Berenson GS (1985b) Dietary studies of children from a biracial population: intakes of vitamins in 10- and 13-year-olds. Journal of the American College of Nutrition 4, 539-552.

Food and Agriculture Organization/World Health Organization/ United Nations University (1985) Energy and Protein Requirements. Report of a Joint Expert Consultation. WHO Technical Report Series no. 724. Geneva: WHO.

Frank GC, Berenson GS, Schilling PE \& Moore MC (1977) Adapting the 24-hr. recall for epidemiologic studies of schoolchildren. Journal of the American Dietetic Association 71, 26-31.

Frank G, Nicklas T, Webber L, Major C, Miller JF \& Berenson GA (1992) A food frequency questionnaire for adolescents: defining eating patterns. Journal of the American Dietetic Association 92, 313-318.

Frost Andersen L, Nes M, Lillegaard IT, Sandstad B, Bjornebøe G-EAa \& Drevon CA (1995) Evaluation of a quantitative food frequency questionnaire used in a group of Norwegian adolescents. European Journal of Clinical Nutrition 49, 543-554.

Gallagher ML, Farrior E, Broadhead L, Gillette LS, Rowe ML, Somes G, West P \& Kolasa KM (1993) Development and testing of a food frequency recall instrument for describing dietary patterns in adults and teenagers. Nutrition Research 13, 177-188.

Garner MD, Olmsted MP, Bohr Y \& Garfinkel EP (1982) The Eating Attitudes Test: psychometric features and clinical correlates. Psychological Medicine 12, 871-878.

Goldberg GR, Black AE, Jebb SA, Cole TJ, Murgatroyd PR, Coward WA \& Prentice AM (1991) Critical evaluation of energy intake data using fundamental principles of energy physiology: 1. Derivation of cut-off limits to identify under-recording. European Journal of Clinical Nutrition 45, 569-581.

Hammond J, Nelson M, Chinn S \& Rona RJ (1993) Validation of a food frequency questionnaire for assessing dietary intake in a study of coronary heart disease risk factors in children. European Journal of Clinical Nutrition 47, 242-250.

Haraldsdóttir J \& Hermansen B (1995) Repeated 24-h recalls with young schoolchildren. A feasible alternative to diet history from parents? European Journal of Clinical Nutrition 49, 729-739. 
Hartman AM, Brown CC, Palmgren J, Pietinen P, Verkasalo M, Myer D \& Virtamo J (1990) Variability in nutrient and food intakes among older middle-aged men. American Journal of Epidemiology 132, 999-1012.

Hill AJ, Draper E \& Stack J (1994) A weight on children's minds: body shape dissatisfactions at 9-years old. International Journal of Obesity 18, 383-389.

Hill AJ \& Robinson A (1991) Dietary concerns have a functional effect on the behaviour of nine-year-old girls. British Journal of Clinical Psychology 30, 265-267.

Hill AJ \& Silver EK (1995) Fat, friendless and unhealthy: 9-year old children's perceptions of body shape stereotypes. International Journal of Obesity 19, 423-430.

Huenemann RL \& Turner D (1942) Methods of dietary investigation. Journal of the American Dietetic Association 18, $562-568$.

Jenner DA, Neylon K, Croft S, Beilin LJ \& Vandongen R (1989) A comparison of methods of dietary assessment in Australian children aged 11-12 years. European Journal of Clinical Nutrition 43, 663-673.

Johnson RK, Driscoll P \& Goran MI (1996) Comparison of multiple-pass 24-hour recall estimates of energy intake with total energy expenditure determined by the doubly labeled water method in young children. Journal of the American Dietetic Association 96, 1140-1144.

Kaskoun MC, Johnson RK \& Goran MI (1994) Comparison of energy intake by semiquantitative food-frequency questionnaire with total energy expenditure by the doubly labeled water method in young children. American Journal of Clinical Nutrition 60, 43-47.

Kelder SH, Perry CL, Klepp K-I \& Lytle LL (1994) Longitudinal tracking of adolescent smoking, physical activity and food choice behaviors. American Journal of Public Health 84, $1121-1126$.

Kersting M, Sichert-Hellert W, Lausen B, Alexy U, Manz F \& Schöch G (1998) Energy intake of 1 to 18 year old German children and adolescents. Zeitschrift für Ernährungswissenschaft 37, 47-55.

Kirkley BG \& Burge JC (1989) Dietary restriction in young women: issues and concerns. Annals of Behavioural Medicine 11, 66-71.

Klesges RC, Hanson CL, Eck LH \& Durff AC (1988) Accuracy of self-reports of food intake in obese and normal weight individuals: effects of parental obesity on reports of children's dietary intake. American Journal of Clinical Nutrition 48, 1252-1256.

Klesges RC, Klesges LM, Brown G \& Frank GC (1987) Validation of the 24-hour dietary recall in preschool children. Journal of the American Dietetic Association 87, 1383-1385.

Lauer RM, Lee J \& Clarke WR (1988) Factors affecting the relationship between childhood and adult cholesterol levels: the Muscatine Study. Pediatrics 82, 309-318.

Livingstone MBE, Prentice AM, Coward WA, Strain JJ, Black AE, Davies PSW, Stewart CM, McKenna PG \& Whitehead RG (1992) Validation of estimates of energy intake by weighed dietary record and diet history in children and adolescents. American Journal of Clinical Nutrition 56, 29-35.

Lytle LA, Nichaman MZ, Obarzanek E, Glovsky E, Montgomery D, Nicklas T, Zive M \& Feldman H (1993) Validation of 24-hour recalls assisted by food records in third-grade children. Journal of the American Dietetic Association 93, 1431-1436.

Maloney MJ, McGuire J \& Daniels SR (1988) Reliability testing of a child's version of the Eating Attitudes Test. Journal of the American Academy of Child and Adolescent Psychiatry 5, 541-543.
Maloney MJ, McGuire J, Daniels SR \& Specker B (1989) Dieting behaviour and eating attitudes in children. Pediatrics 84, 482-489.

Marr JW \& Heady JA (1986) Within- and between-person variation in dietary surveys: number of days needed to classify individuals. Human Nutrition Applied Nutrition 40A, 347-364.

Mendelson BK \& White DR (1982) Relation between body-esteem and self-esteem of obese and normal children. Perceptual Motor Skills 54, 899-905.

Meredith A, Matthews A, Zickefoose M, Weagley E, Wayave M \& Brown EG (1951) How well do school children recall what they have eaten? Journal of the American Dietetic Association 27, 749-751.

Michela JL \& Contento IR (1984) Spontaneous classification of foods by elementary school-aged children. Health Education Quarterly 11, 57-76.

Miller JZ, Kimes T, Hui S, Andon MB \& Johnston CC (1991) Nutrient intake variability in a pediatric population: implications for study design. Journal of Nutrition 121, 265-274.

Moore MC, Judlin BC \& Kennemur P McA (1967) Using graduated food models in taking diet histories. Journal of the American Dietetic Association 51, 447-450.

Must A, Jacques PF, Dallal GE, Bajema CJ \& Dietz WH (1992) Long-term morbidity and mortality of overweight adolescents: a follow-up of the Harvard Growth Study of 1922 to 1935. New England Journal of Medicine 327, 1350-1355.

Nelson M, Black AE, Morris JA \& Cole TJ (1989) Between- and within-subject variation in nutrient intake from infancy to old age: estimating the number of days required to rank dietary intakes with desired precision. American Journal of Clinical Nutrition 50, 155-167.

Nieto FJ, Szklo M \& Comstock GW (1992) Childhood weight and growth rate as predictors of adult mortality. American Journal of Epidemiology 136, 201-213.

Nylander I (1971) The feeling of being fat and dieting in a school population. Acta Socio Medica Scandinavica 3, 17-26.

Persson LA \& Carlgren G (1984) Measuring childen's diets: evaluation of dietary assessment techniques in infancy and childhood. International Journal of Epidemiology 13, 506-517.

Porkka KVK, Viikari JSA, Taimela S, Dahl M \& Akerblom HK (1994) Tracking and predictiveness of serum lipid and lipoprotein measurements in childhood: a 12-year follow-up. The Cardiovascular Risk in Young Finns Study. American Journal of Epidemiology 140, 1096-1110.

Prentice AM, Black AE, Coward WA, Davies HL, Goldberg GR, Murgatroyd PR, Ashford J, Sawyer M \& Whitehead RG (1986) High levels of energy expenditure in obese women. British Medical Journal 292, 983-987.

Raitakari OT, Porkka KVK, Räsänen L, Rönnemaa T \& Viikari JS (1994) Clustering and 6-year cluster-tracking of serum total cholesterol, HDL-cholesterol and diastolic blood pressure in children and young adults. The Cardiovascular Risk in Young Finns Study. Journal of Clinical Epidemiology 47, 1085-1093.

Robson PJ, Gray AM, Livingstone MBE, Cran GW, Strain JJ, Savage JM \& Boreham CAG. Tracking of nutrient intakes in adolescence: the experiences of the Young Hearts Project, Northern Ireland. British Journal of Nutrition (In the Press).

Rockett HRH, Wolf AM \& Colditz GA (1995) Development and reproducibility of a food frequency questionnaire to assess diets of older children and adolescents. Journal of the American Dietetic Association 95, 336-340.

Samuelson G (1970) An epidemiological study of child health and nutrition in a northern Swedish county Nutrition and Metabolism 12, 321-340.

Sempos CT, Johnson NE, Smith EL \& Gilligan C (1985) Effects of intraindividual and interindividual variation in repeated dietary records. American Journal of Epidemiology 121, 120-130. 
Simons-Morton BG, Baranowski T, Parcel GS, O'Hara NM \& Matteson RC (1990) Children's frequency of consumption of foods high in fat and sodium. American Journal of Preventive Medicine 6, 218-227.

Singer MR, Moore LL, Garrahie EJ \& Ellison RC (1995) The tracking of nutrient intake in young children: the Framingham Children's Study. American Journal of Public Health 85, 1673-1677.

Smith AF, Jobe JB \& Mingay DJ (1991) Retrieval from memory of dietary information. Applied Cognitive Psychology 5, 269-296.

Srinivasan SR, Bao W, Wattigney WA \& Berenson GS (1996) Adolescent overweight is associated with adult overweight and related multiple cardiovascular risk factors: the Bogalusa Heart Study. Metabolism 45, 235-240.

Stein AD, Shea S, Basch CE, Contento IR \& Zybert P (1991) Variability and tracking of nutrient intakes of preschool children based on multiple administrations of the 24-hour dietary recall. American Journal of Epidemiology 134, 1427-1437.

Tarasuk V \& Beaton GH (1992) Statistical estimation of dietary parameters: implications of patterns in within-subject variation - a case study of sampling strategies. American Journal of Clinical Nutrition 55, 22-27.

Torun B, Davies PSW, Livingstone MBE, Paolisso M, Sackett R \& Spurr GB (1996) Energy requirements and dietary energy recommendations for children and adolescents 1 to 18 years old. European Journal of Clinical Nutrition 50, Suppl. 1, S37-S81.

Twisk JWR, Kemper HCG, van Mechelen W \& Post GB (1997) Tracking of risk factors for coronary heart disease over a 14-year period: a comparison between lifestyle and biologic risk factors with data from the Amsterdam Growth and Health Study. American Journal of Epidemiology 145, 888-898.

Van Horn LV, Gernhofer N, Moag-Stahlberg A, Farris R, Hartmuller G, Lasser VI, Stumbo P, Craddick S \& Ballew C (1990) Dietary assessment in children using electronic methods: telephones and tape recorders. Journal of the American Dietetic Association 90, 412-416.
Van Strien T, Frijters JER, Bergers GPA \& Defares PB (1986) Dutch eating behaviour questionnaire for assessment of restrained, emotional and external eating behaviour. International Journal of Eating Disorders 5, 295-315.

Wardle J \& Beales S (1986) Restraint, body image and food attitudes in children from 12-18 years. Appetite 7, 209-217.

Wardle J \& Marsland L (1990) Adolescent concerns about weight and eating: a social-developmental perspective. Journal of Psychosomatic Research 34, 377-391.

Wattigney WA, Webber LS, Srinivasan SR \& Berenson GS (1995) The emergence of clinically abnormal levels of cardiovascular risk factor variables among young adults: the Bogalusa Heart Study. Preventive Medicine 24, 617-626.

Webber LS, Srinivasan SR, Wattigney WA \& Berenson GS (1991) Tracking of serum lipids and lipoproteins from childhood to adulthood: the Bogalusa Heart Study. American Journal of Epidemiology 133, 884-889.

Weber JL, Cunningham-Sabo L, Skipper B, Lytle L, Stevens J, Gittelsohn J, Anliker J, Heller K \& Pablo JL (1999) Portionsize estimation in second- and third-grade American Indian children. American Journal of Clinical Nutrition 69, Suppl., 782S-787S.

Welten DC, Kemper HCG, Post GB, Van Staveren WA \& Twisk JWR (1997) Longitudinal development and tracking of calcium and dairy intake from teenager to adult. European Journal of Clinical Nutrition 51, 612-618.

Young CM, Chalmers FW, Church HN, Clayton MM, Hagan GC, Steele BF, Tucker RE \& Foster WD (1952) Subject's ability to estimate food portions. Massachusetts Experimental Station Bulletin 469, 63-77.

Yuhas JA, Bolland JE \& Bolland TW (1989) The impact of training, food type, gender and container size on the estimation of food portion sizes. Journal of the American Dietetic Association 89, 1473-1477. 